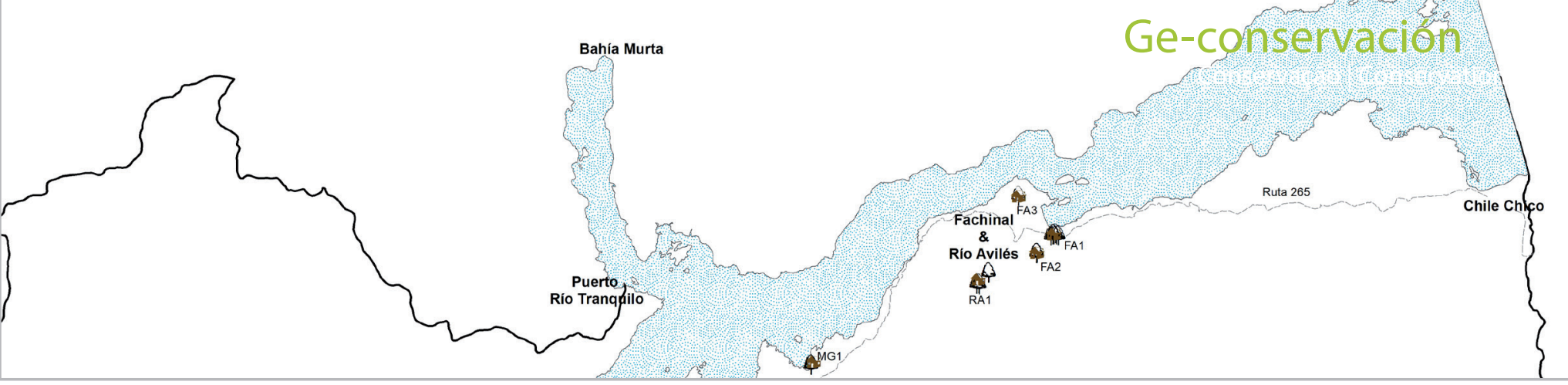

\title{
Arquitectura en adobe y quincha: construcción de una identidad en torno a los recursos naturales de la ribera del Lago General Carrera en la región de Aysén, Chile
}

\author{
Carlos Castillo Levicoy, Constanza Pérez Lira
}

\begin{abstract}
Resumen: Se presentan los resultados del estudio de diez construcciones en adobe y quincha, ubicadas en los sectores de Fachinal, Río Avilés y Mallín Grande (ribera sur-poniente del lago General Carrera), comuna de Chile Chico, región de Aysén, Chile. El objetivo fue identificar aquellas técnicas constructivas locales propias del territorio, caracterizando los materiales utilizados, los periodos de asentamiento y construcción, y registrando su planimetría. Las construcciones más antiguas corresponden a las erigidas por los pobladores del sector estudiado entre los años 1925 y 1929. En todas prevalece la autoconstrucción en tierra, madera y piedra, cuyo estado actual de deterioro hace que sea imprescindible su caracterización para su salvaguarda y puesta en valor como elementos identitarios de la arquitectura vernácula de Aysén.
\end{abstract}

Palabras clave: arquitectura vernácula, adobe, quincha, madera, región de Aysén

\section{Adobe and quincha architecture: building identity from General Carrera Lakeshore's natural resources in the Aysén region, Chile}

\begin{abstract}
The results from the study on ten adobe and quincha buildings located in the areas of Fachinal, Aviles River and Mallín Grande (south-west bank of Lake General Carrera) from the Aysén Region, Chile, are displayed in this document. With the objective of identifying the local building techniques and the material used, settling and building periods were characterized, along with its planimetry registered. The oldest date back to 1925 to 1929. Most were self-assembled using soil, wood, and stone. Their current deteriorated state of preservation demands its characterization for its protection and value enhancement as Aysén vernacular architecture.
\end{abstract}

Keyword: vernacular architecture, adobe, wattle-and-daub, wood, Aysen region

\section{Arquitetura em adobe e quincha: construção de uma identidade em torno dos recursos naturais das margens do Lago General Carrera na região de Aysén, Chile}

Resumo: São apresentados os resultados do estudo de dez edifícios em adobe e quincha, localizados nas regiões de Fachinal, Río Avilés e Mallín Grande (margem sudoeste do Lago General Carrera), distrito de Chile Chico, região de Aysén, Chile. O objetivo foi identificar as técnicas de construção locais próprias do território, caracterizando os materiais utilizados, os períodos de povoamento e construção e registando a sua planimetria. As construções mais antigas correspondem às erguidas pelos habitantes da região estudada entre os anos 1925 e 1929. Em todas elas prevalece a autoconstrução em terra, madeira e pedra, cujo atual estado de degradação torna a sua caracterização imprescindível para a sua salvaguarda e valorização como elementos de identidade da arquitetura vernácula de Aysén.

Palavras-chave: arquitetura vernácula, adobe, quincha, madeira, região de Aysén 


\section{Introducción}

Una casa antigua y en pie es testigo de una vida pasada o es una ventana al pasado, ofreciendo la oportunidad de reconstruir la historia de vida de sus moradores, de la utilización de los elementos naturales disponibles y de la transformación del paisaje (Castillo y Pérez 2019: 107). En cada arquitectura vernácula con distinta materialidad se observa la capacidad del constructor/a de ver y anticipar (Fullerton y Medina 2017: 130), desde sus sentidos agudizados, la ubicación exacta de emplazamiento, de los puntos de cortes, la dureza y resistencia del material utilizado, el peso correcto de una pieza de madera, de un bloque de adobe, de una piedra y de la mezcla correcta del barro con paja, guano y ramas (Tomasi y Rivet 2009: 15). Este saber adquirido desde la experiencia del hacer, permitió definir aspectos tan básicos como la altura de un muro, la colocación correcta de los materiales para una esquina, para un zócalo como cimiento y sobre cimiento, el ancho y largo de la planta, el tamaño correcto para una ventana y para una puerta, así como para determinar el peso adecuado de la techumbre (Tomasi 2012: 15; Rivera 2012: 167; Fullerton y Medina 2017: 160).

Los elementos arquitectónicos en tierra y madera existentes en la zona de Fachinal, Río Avilés y Mallín Grande (ribera sur-poniente del lago General Carrera), ubicados en la comuna de Chile Chico, Región de Aysén, Chile, dan cuenta de una enorme riqueza cultural, donde se conjugan tradiciones y costumbres surgidas y moldeadas al modo de habitar este territorio. Familias Ilegadas principalmente desde el territorio argentino se trasladaron a través del lago General Carrera y por tierra desde Chile Chico por el oriente y desde el mismo territorio aysenino desde Puerto Guadal por el poniente. Se abrieron caminos, se trasladaron el ganado y los víveres, se recorrieron los valles interiores en búsqueda de las mejores pasturas y aguas, se hicieron las huertas y las quintas (Castillo y Pérez 2019: 107), se extrajo la mejor madera desde los bosques aledaños, y la tierra y la piedra para construir el refugio, es decir la primera casa (Pérez et al. 2018: 21). La arquitectura vernácula en adobe y quincha -conocida también cómo bahareque, enjarre o embarrado, pared francesa y/o wattle-and-daub- en esta zona de estudio presenta una realidad compleja debido al desconocimiento y a la falta de valorización de la técnica constructiva y al estado de conservación de los inmuebles por parte de los propios dueños y de la comunidad local (Castillo 2015: 19), aspectos que la están Ilevando hacia una inexorable desaparición en el corto plazo.

Bajo el escenario actual cabe preguntarse ¿Qué características constructivas hacen especial y única a la arquitectura vernácula de este territorio? Para dar respuesta a este interrogante el presente trabajo tiene como objetivo identificar aquellas técnicas constructivas locales propias del territorio, llevando a cabo el registro planimétrico de diferentes casos de estudio, la identificación de los materiales utilizados y de los periodos de asentamiento y construcción, bajo la hipótesis de que "La arquitectura vernácula representa en su génesis, aquella sabiduría constructiva mejor asimilada y expresada por los pobladores que se establecieron en la ribera sur-poniente del Lago General Carrera, región de Aysén".

\section{Metodología}

\section{- Levantamiento de datos y análisis}

Durante el año 2019, se llevó a cabo la selección y caracterización de 10 construcciones en "adobe y quincha" insertas en los sectores rurales de Mallín Grande, Fachinal y Río Avilés, sectores pertenecientes a la ribera sur-poniente del Lago General Carrera de la región de Aysén [Figura

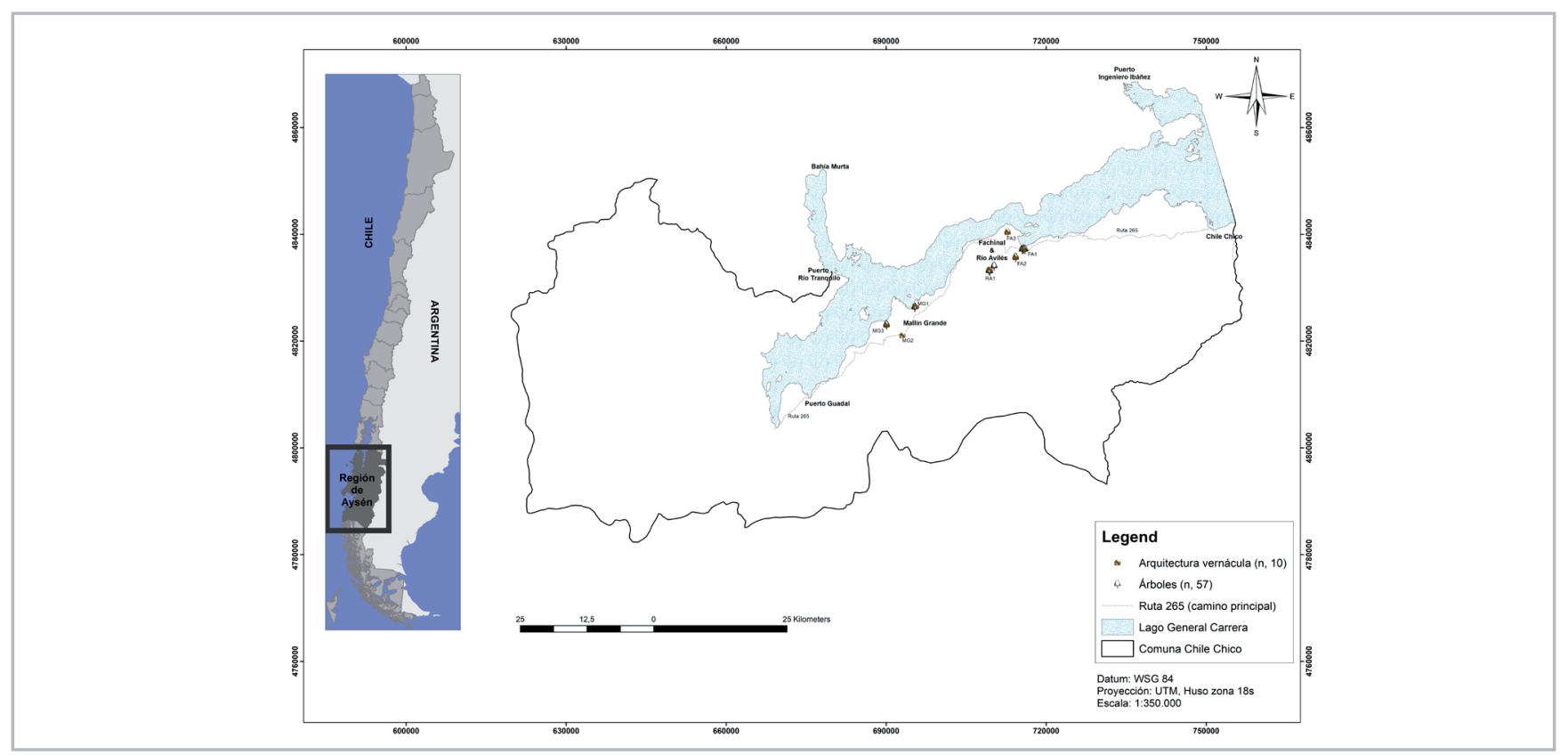

Figura 1.- Distribución geográfica de la arquitectura y árboles estudiados. 
1]. Dicha selección de casos se basó en información preliminar recogida de antiguos pobladores de la zona, eligiendo así los más representativos en su técnica y de mayor antigüedad. El área de trabajo se caracteriza por estar ubicada en un clima templado de microclima (Csb) con precipitaciones que van desde los $200 \mathrm{~mm}$ a los $500 \mathrm{~mm}$ anuales y con una temperatura media de 9,4 ${ }^{\circ} \mathrm{C}$ (Dirección Meteorológica de Chile 2010: 1-3; Hepp y Stolpe 2014: 37).

En los sectores se recabó la siguiente información:

a) Identificadas las construcciones (casa principal), se midieron en planta y elevación con la ayuda de una huincha de distancia y métrica, conjuntamente se realizó un levantamiento fotográfico del exterior e interior de cada una de estas con una Cámara CANON EOS D60 y Trípode Manfrotto. Se caracterizó su materialidad constructiva y dimensiones de las piezas trabajadas «vigas, soleras, bloques de adobes, piedras, basas del piso y tablas, encintado del techo, entre otras», y se georreferenció su ubicación espacial utilizando un GPS MONTANA 680.

b) Selección e identificación de árboles frutales, álamos, ornamentales y nativos, para su estudio dendrocronológico: La altura total del árbol se midió con la ayuda de un HIPSÓMETRO SUNTTO y se midió el diámetro del fuste con una forcípula (HAGLÖF) y huincha diamétrica (JACKSON, MS). Se extrajo una muestra de tarugo tomada a los 30 centímetros de altura desde la base del árbol con un taladro de incremento FINNFORCE de 16 pulgadas y HAGLÖF de 16 y 20 pulgadas. Esto se realizó en árboles introducidos y plantados por el primer propietario, así como de algunas especies nativas en torno al conjunto construido. Posteriormente estas fueron montadas en molduras de madera y lijadas progresivamente con distintas granulometrías (secuencia de granos grueso a fino), hasta que los anillos de crecimiento fueran claramente distinguibles. Con el uso de un MICROSCOPIO ESTÉREO 3.5X-90X ZOOM, SIMUL-FOCAL TRINOCULAR, se contaron los anillos de crecimiento anual (periodos de crecimiento vegetativo) y para aquellas muestras en que no se obtuvo el centro de la médula se estimaron los anillos faltantes utilizando la fórmula descrita por Duncan 1989. Se utiliza la técnica de dendrocronología para este estudio con el fin de determinar a ciencia cierta la antigüedad de las primeras especies introducidas por cada poblador en la zona de estudio en específico. El año obtenido para cada caso, se contrasta con la información conseguida a partir de la entrevista personal realizada a cada propietario, con el fin de poder atenerse a un año exacto de asentamiento del poblador/a.

c) Entrevistas orales; Se llevaron a cabo entrevistas semiestructuradas a los dueños originales y/o familiares directos que utilizaron estas construcciones con una Grabadora Digital de Sonidos PCM D50 SONY 96kHz/24 bit. Esta información complementaria permitió conocer el periodo de construcción de los inmuebles para su contraste con los datos de edad obtenidos del estudio dendrocronológico. Conjuntamente esta información permitió contextualizar el uso que tuvieron los inmuebles, las técnicas constructivas utilizadas, y el tipo de recurso natural utilizado.

Para el análisis de los principales resultados obtenidos se utilizaron los programas: ArcGis, el Software SigmaPlot 10.0 y el software AutoCAD.

\section{Resultados}

\section{-Construcciones y materialidad}

- Poblador Modesto Basualto (MG1): La casa construida en la década de 1950, se ubicó al lado del embarcadero antiguo de la localidad de Mallín Grande. Su volumetría es simple y cubierta de 4 aguas [Figura 2]. Su materialidad se compone principalmente de bloques de adobe crudo cuyo tamaño promedio es de $35 \times 15 \times 20$ centímetros y revocados con mortero de barro, posee una base (cimiento y sobre cimiento) de piedras de tamaño irregular enterradas a $30 \mathrm{~cm}$ aproximadamente y 15 a 20 $\mathrm{cm}$ sobre el suelo. La techumbre es de madera, revestida con tejuela artesanal rajada de 22 pulgadas de largo, por 4 $1 / 2$ a 6 pulgadas de ancho y espesor sobre los 6 milímetros. Las cintas del entejuelado ${ }^{[1]}$ son labradas de $3 \times 2$ pulgadas y separadas cada $22 \mathrm{~cm}$. Posee vigas de $5 \times 4$ pulgadas, la soleras horizontales de $5 \times 4$ pulgadas, y piezas de cercha de $3 \times 4$ pulgadas, todas labradas a hacha. El piso se compone de tablones labrados de $6 \times 3$ pulgadas. El programa se distribuye en un dormitorio, cocina y corredor de entrada, con una superficie total de $52 \mathrm{~m}^{2}$. Las maderas utilizadas corresponden a las especies $N$. pumilio, $N$. betuloides y $N$. antartica.

- Pobladores Juan Burgos Manrique y Paulina Hermosilla Solís (MG2): La casa construida entre los años 1925 a 1935, se ubica a 1 kilómetro de la localidad de Mallín Grande (entrada oeste). Su volumetría es simple y mantiene una cubierta a 4 aguas [Figura 2]. Su materialidad se compone principalmente de bloques de adobe crudo cuyo tamaño promedio es de $19 \times 28 \times 10 \mathrm{~cm}$ y revocados con mortero de barro, posee una base de piedras de tamaño irregular enterradas a $30 \mathrm{~cm}$ aproximadamente y 15 a $20 \mathrm{~cm}$ sobre el suelo. La techumbre es de madera, revestida con tejuela artesanal rajada de 21 a 22 pulgadas de largo, por $4 \frac{1}{2}$ a 6 pulgadas de ancho y espesor sobre los 6 milímetros. Las cintas del entejuelado son de $3 \times 1$ y $2 \times 1$ pulgadas, separadas cada $15 \mathrm{~cm}$. Posee vigas de $5 \times 4$ pulgadas, la soleras horizontales de $3 \times 4 \frac{1}{2}$ pulgadas, $y$ piezas de cercha de $3 \times 3$ pulgadas, todas labradas a hacha. El piso se compone de tablas aserradas de $6 \times 1$ pulgadas. El programa se compone de dos dormitorios y cocina, con una superficie total de $35 \mathrm{~m} 2$. Las maderas utilizadas corresponden a las especies $N$. pumilio, N. betuloides y $N$. antartica. 


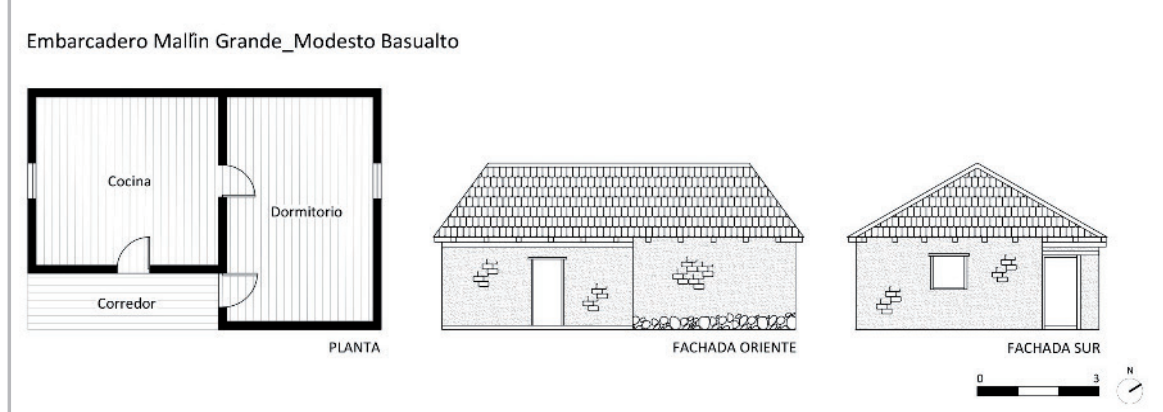

Casa_Burgos Hermosilla
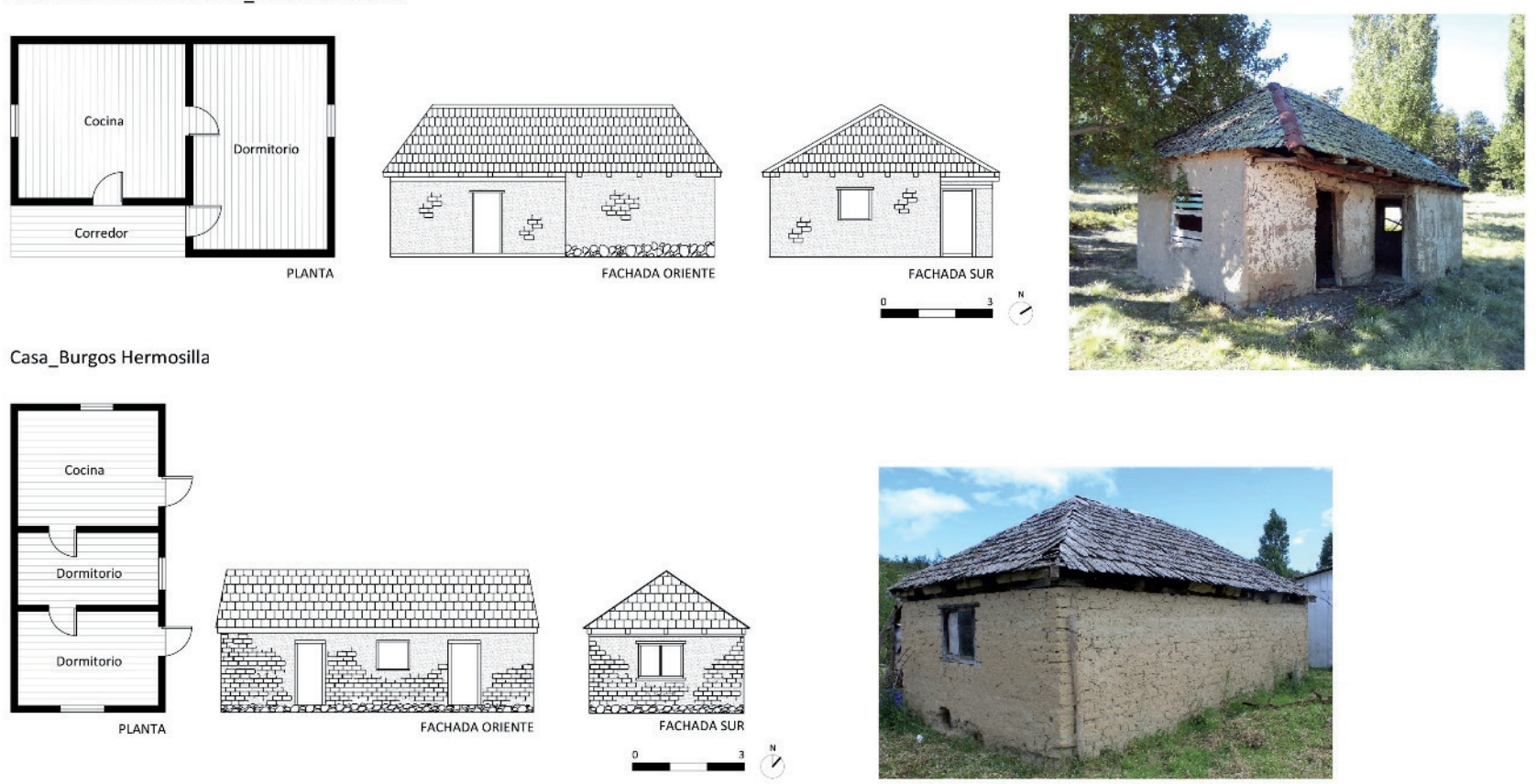

Figura 2.- Proyección planimétrica MG1 y MG2.

- Poblador desconocido (s.i.) (MG3): La casa construida entre los años 1925 y 1935, se ubica a orillas del Lago General Carrera a 3,5 km de la localidad de Mallín Grande (entrada oeste). Su volumetría es simple y mantiene una cubierta a 2 aguas [figura 3]. Su materialidad se compone principalmente por una pared de barro aglomerado con un entramado de ramas, varas y huesos de animales, y con mortero de barro, técnica conocida como "Quincha, Bajareque y/o Pared Francesa". Posee un espacio de

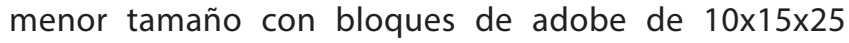
$\mathrm{cm}$. El cimiento se compone de una base de piedras de tamaño irregular enterradas a $35 \mathrm{~cm}$ aproximadamente y 15 a $25 \mathrm{~cm}$ sobre el suelo. La techumbre actual [2] es de madera, revestida con tejuela artesanal rajada de 21 a 22 pulgadas de largo, por $4 \frac{1}{2}$ a 6 pulgadas de ancho y espesor sobre los 7 milímetros. Las cintas del entejuelado son de $3 \times 1$ y $2 \times 1$ pulgadas, separadas cada $15 \mathrm{~cm}$. Posee vigas de 4x3, 4x4 y 4x6 pulgadas, la soleras horizontales de $6 \times 3$ pulgadas, piezas de cercha de $4 \times 2$ y $4 \times 3$ pulgadas, y pilares de $4 \times 3$ pulgadas, todas labradas a hacha. El piso se compone de tablas aserradas de $5 \frac{1}{2} \times 1$ y $4 \times 1$ pulgadas. El programa se distribuye en tres dormitorios y cocina-comedor, con una superficie total de $86 \mathrm{~m}^{2}$. Las maderas utilizadas corresponden a las especies $N$. pumilio, C. patagonicus, C. integerrima, $C$. macrocarpa y $N$. betuloides.

- Poblador Uberlindo Fica Rivera (FA1): La "casa vieja" fue construida entre los años 1925 y 1930, se ubica en el sector de Fachinal. Su volumetría es simple y mantiene una cubierta a 2 aguas [Figura 4]. Su materialidad se compone principalmente de bloques de adobe crudo cuyo tamaño promedio es de $20 \times 23 \times 10$ centímetros y revocados con mortero de barro, posee una base de piedras de tamaño irregular enterradas a $35 \mathrm{~cm}$ aproximadamente y 50 a 60 $\mathrm{cm}$ sobre el suelo. La techumbre es de madera, revestida con tejuela artesanal rajada de 21-22 pulgadas de largo, por $4 \frac{1}{2}$ a 6 pulgadas de ancho y espesor sobre los 7 milímetros. Las cintas del entejuelado son labradas de $3 \times 2$ y $2 \times 2$ pulgadas y separadas cada 15 y $20 \mathrm{~cm}$. Posee vigas de $3 \times 4,3 \times 3$ y $4 \times 5$ pulgadas, la soleras horizontales de $3 \times 3$ y $3 \times 4$ pulgadas, y piezas de cercha de $3 \times 4$ y $3 \times 5$ pulgadas, todas labradas a hacha. El piso es de tierra. El programa se distribuye en una cocina-comedor y un dormitorio, con una superficie total de $25 \mathrm{~m}^{2}$. Las maderas utilizadas corresponden a las especies $N$. pumilio y Pinus sp.

La "casa nueva" fue construida en la década de 1930, su volumetría es simple y mantiene una cubierta a 2 aguas [Figura 4]. Su materialidad se compone principalmente de bloques de adobe crudo cuyo tamaño promedio es de $20 \times 23 \times 10$ centímetros y revocados con mortero de barro, posee una base de piedras de tamaño irregular enterradas a $35 \mathrm{~cm}$ aproximadamente y 20 a $60 \mathrm{~cm}$ sobre el suelo. La techumbre original en de planchas de zinc. Las cintas del techo son aserradas de $3 \times 2$ pulgadas $y$ separadas cada $30 \mathrm{~cm}$. Posee vigas de $3 \times 4$ y $4 \times 5$ pulgadas, la soleras horizontales de $3 \times 3$ y $3 \times 4$ pulgadas, y piezas de cercha de $4 \times 3$ y $5 \times 3$ pulgadas, todas labradas a hacha. El piso es de tablas aserradas de 8 a 14,5 pulgadas de ancho por 2 pulgadas de espesor. El programa se distribuye en una cocina-comedor y un dormitorio, con una superficie total de $50 \mathrm{~m}^{2}$. Las maderas utilizadas corresponden a las especies N. pumilio y Pinus $s p$. 


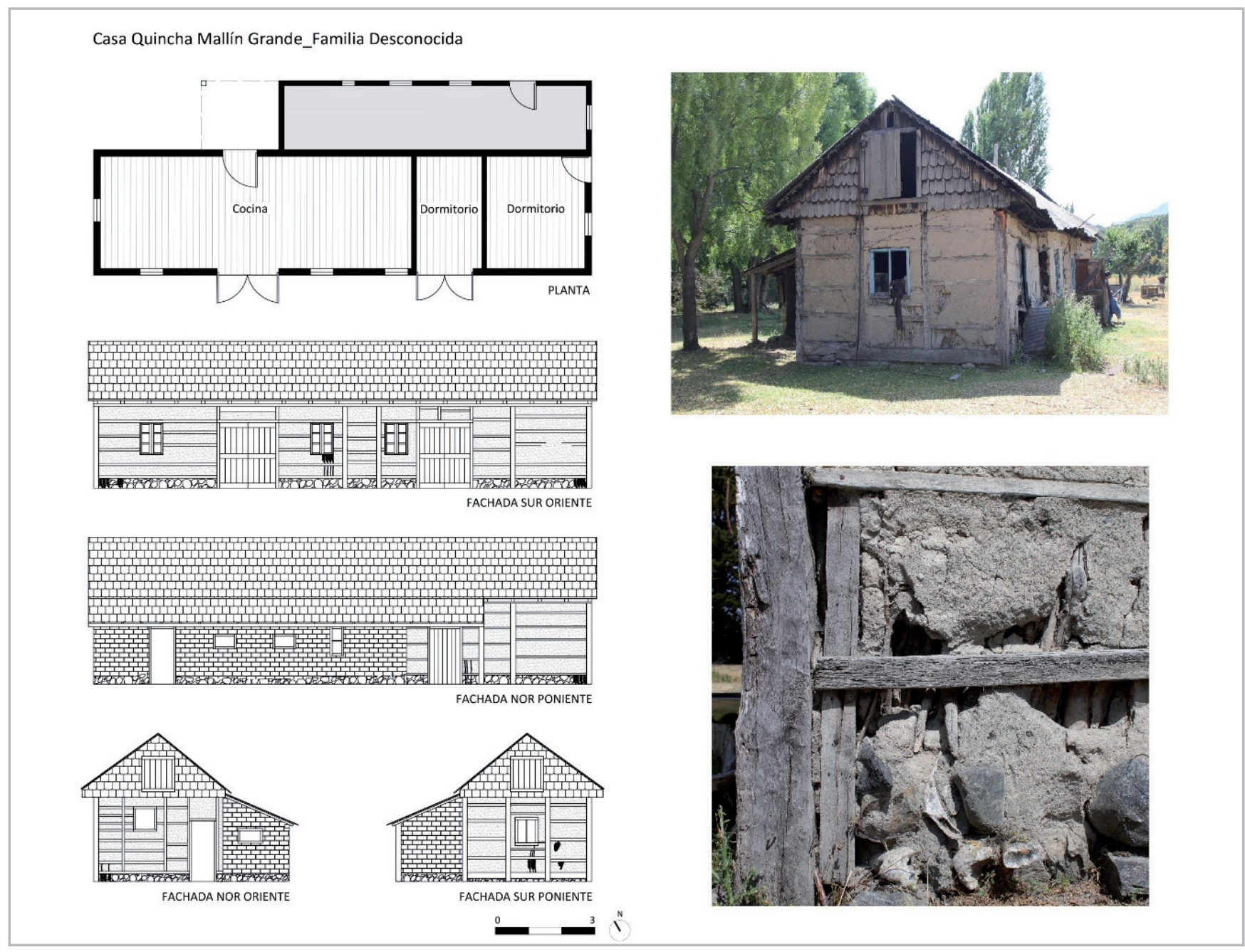

Figura 3.- Proyección planimétrica MG3.
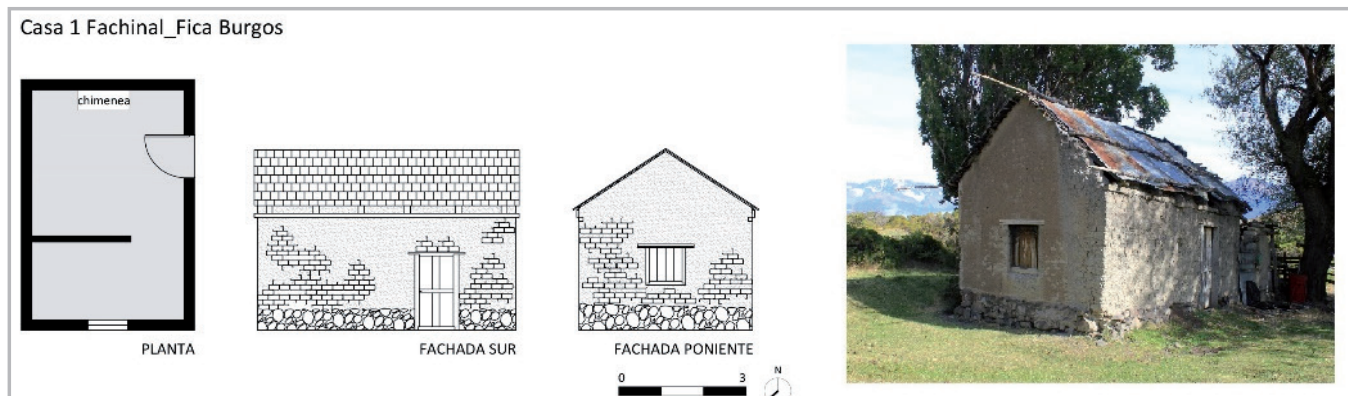

Casa 2 Fachinal_Fica Burgos
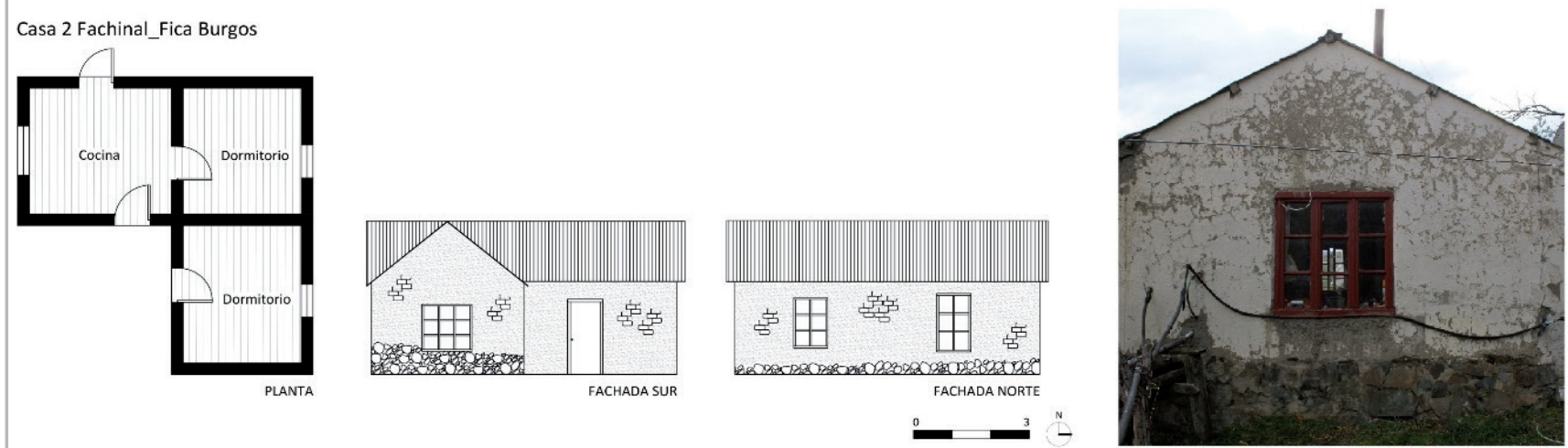

Figura 4.- Proyección planimétrica FA 1. 
-Poblador Manuel Muñoz Muñoz (FA2): La "casa vieja" fue construida entre los años 1925 y 1935, está ubicada en el sector Ilamado "Puesto el Manzano", Fachinal. Este perteneció primeramente al poblador José Ahuil, quien llegó al sector en la década de 1910 en adelante [Figura 5]. Su materialidad se compone principalmente de bloques de adobe crudo cuyo tamaño promedio es de $18 \times 35 \times 13 \mathrm{~cm}$ y revocados con mortero de barro, posee una base de piedras de tamaño irregular enterradas a $35 \mathrm{~cm}$ aproximadamente y 15 a $20 \mathrm{~cm}$ sobre el suelo. La techumbre original de dos aguas es de planchas de zinc ondulado. Las cintas del techo son aserradas de $3 \times 2$ pulgadas y separadas cada 30 $\mathrm{cm}$. Posee vigas de $3 \times 3,3 \times 4,3 \times 5,4 \times 5$ y de $5 \times 5$ pulgadas, la soleras horizontales de $3 \times 3$ y $3 \times 4$ pulgadas, y piezas de cercha de $4 \times 4$ y $4 \times 5$ pulgadas, todas labradas a hacha. El piso es de tablas aserradas de 6, 8 y 9 pulgadas de ancho por 2 pulgadas de espesor. El programa se distribuye en una cocina-comedor y un dormitorio, con una superficie total de $38 \mathrm{~m}^{2}$. Las maderas utilizadas corresponden a las especies $N$. pumilio y Pinus sp.

La "casa nueva" (está en ruinas) fue construida en la década de 1960, y su materialidad se compone principalmente de bloques de adobe crudo cuyo tamaño promedio es de $10 \times 30 \times 20 \mathrm{~cm}$ y revocados con mortero de barro, posee una base de piedras de tamaño irregular enterradas a $40 \mathrm{~cm}$ aproximadamente y 25 a $35 \mathrm{~cm}$ sobre el suelo. La techumbre original es de planchas de zinc ondulado. Las cintas del techo eran aserradas de $3 \times 2$ pulgadas y separadas cada 30 $\mathrm{cm}$. Posee vigas de $3 \times 3,3 \times 4,3 \times 5,4 \times 5$ y de $5 \times 5$ pulgadas, la soleras horizontales de $3 \times 3$ y $3 \times 4$ pulgadas, todas labradas a hacha. El piso es de tablas aserradas de 6, 8 y 9 pulgadas de ancho por 2 pulgadas de espesor. El programa estuvo compuesto por una cocina-comedor y un dormitorio, con una superficie total de $32 \mathrm{~m}^{2}$. Las maderas utilizadas corresponden a las especies N. pumilio y Pinus $s p$.
-Poblador Celestino Epifanio (RA1): El primer puesto y/o rancho de palo partido, apique y canogas fue construido a principios de 1920, y el segundo puesto de veranada fue construido entre los años 1935 y principios de 1940 en el predio de don Celestino Epifanio, se ubica al interior del río Avilés, sector Fachinal. Su volumetría es simple y mantiene cubierta a un agua [Figura 5]. Su materialidad se compone principalmente por varas de ciprés, barro mezclado con ramas, turba y pequeñas piedras, técnica conocida como "Quincha, Bahareque y/o Pared Francesa". La techumbre original fue de canogas labradas a hacha mientras que la actual es de zinc ondulado. Vigas redondas de 10 a 20 $\mathrm{cm}$ de diámetro. Pies derechos de sección redonda de 20 a $25 \mathrm{~cm}$ de diámetro en su parte más gruesa y de 12 a 18 $\mathrm{cm}$ en su parte más delgada. No posee cerchas, y el piso es de tierra. El programa considera una sola habitación donde se distribuye la cocina (tacho), la cama, bancos y repisas para los víveres. La superficie total es de $15 \mathrm{~m}^{2}$. Las maderas utilizadas corresponden a las especies $P$. uviferum, C. patagonicus, Azara sp., Bacharis sp. y N. betuloides.

-Poblador Santos Quezada (FA3): el rancho fue construido en la década de 1940, está ubicado en el sector de Fachinal. Su materialidad se compone principalmente por una pared de barro aglomerado con un entramado de ramas, cintas labradas de $2 \times 2,2 \times 3$ y $3 \times 3$ pulgadas y cubierta con mortero de barro, técnica conocida como "Quincha, Bahareque y/o Pared Francesa" [Figura 6]. La techumbre actual de un agua es de madera, revestida con tejuela artesanal rajada de 21 a 22 pulgadas de largo, por $41 / 2$ a 6 pulgadas de ancho $y$ espesor sobre los 7 milímetros. Las cintas del entejuelado son de $2 \times 2,2 \times 3$ y $2 \times 4$ pulgadas, separadas cada 10, 15 y 20 $\mathrm{cm}$. Posee vigas de $3 \times 4$ pulgadas, la soleras horizontales de $4 \times 4$ y $4 \times 5$ pulgadas, piezas de cercha de $3 \times 4$ pulgadas, y pies derechos de $6 \times 4$ y $6 \times 5$ pulgadas, todas labradas a hacha. EI piso es de tierra. El programa considera la cocina comedor

Casa 1 El Manzano_José Ahuil

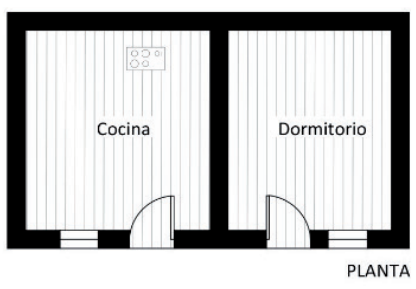

PLANTA

Puesto Quincha_Celestino Epifanio Rio Aviles

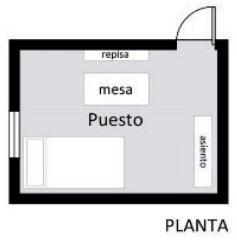

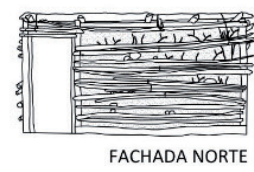

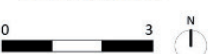

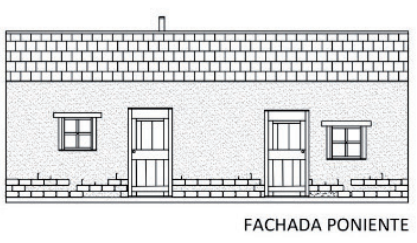

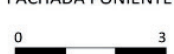

$\stackrel{N}{-}$
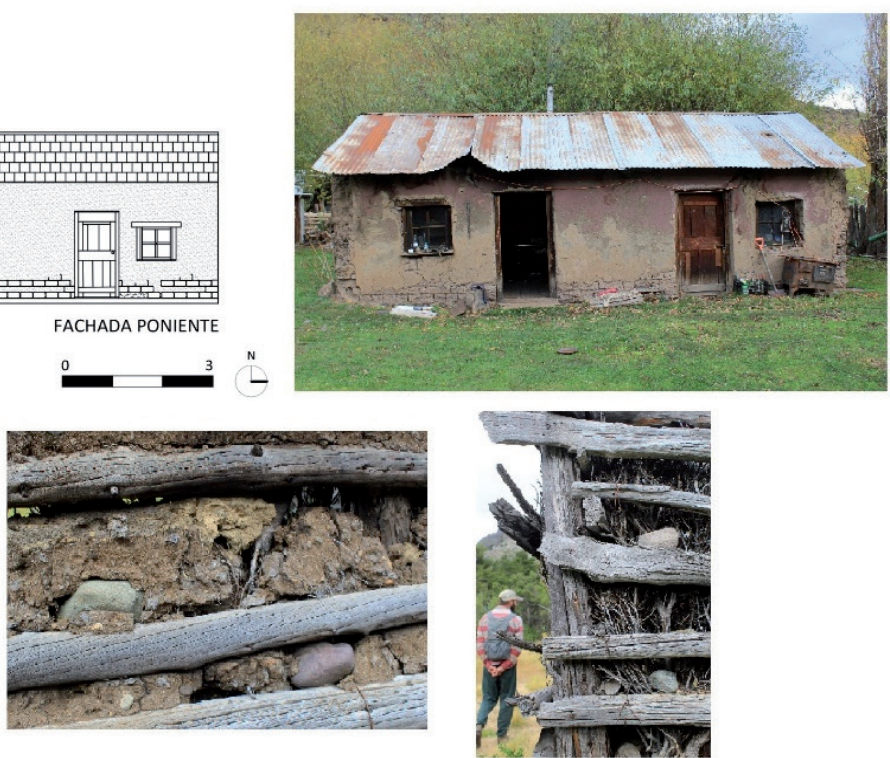

Figura 5.- Proyección planimétrica FA2 y RA1. 
Casa Fachinal_Santos Quezada
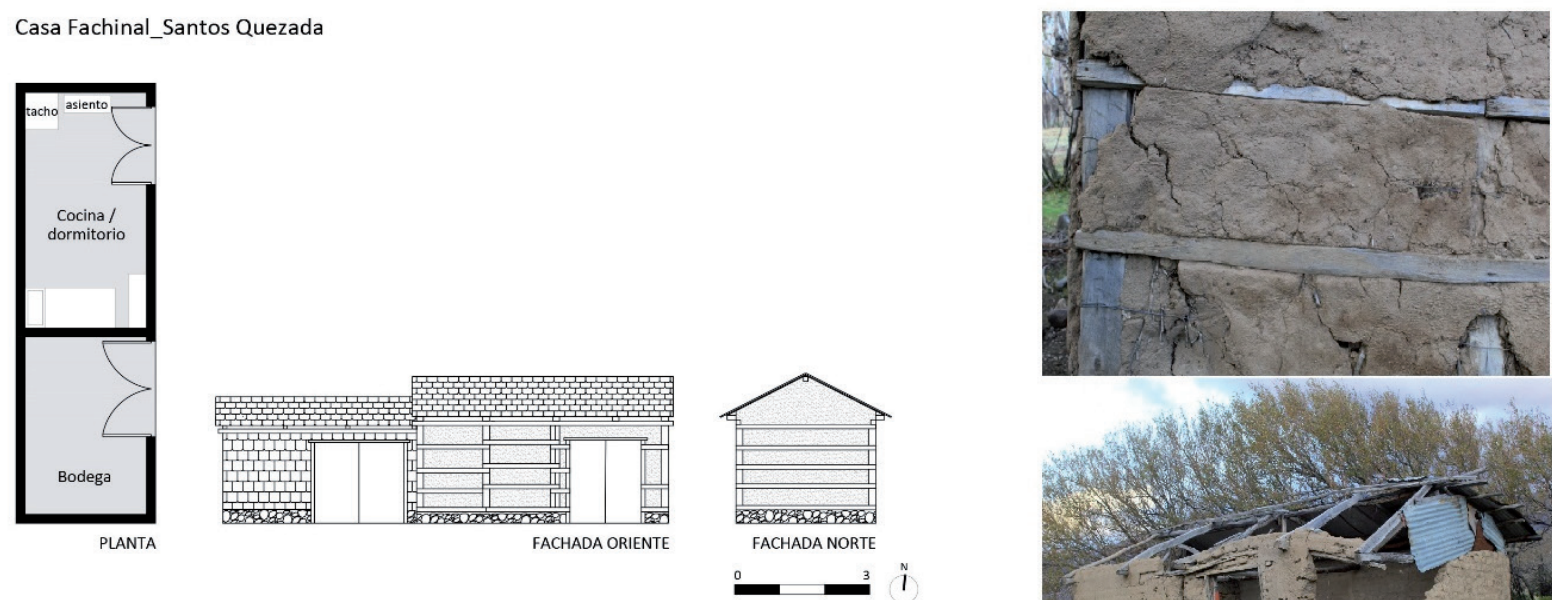

Galpón Fachinal_Santos Quezada
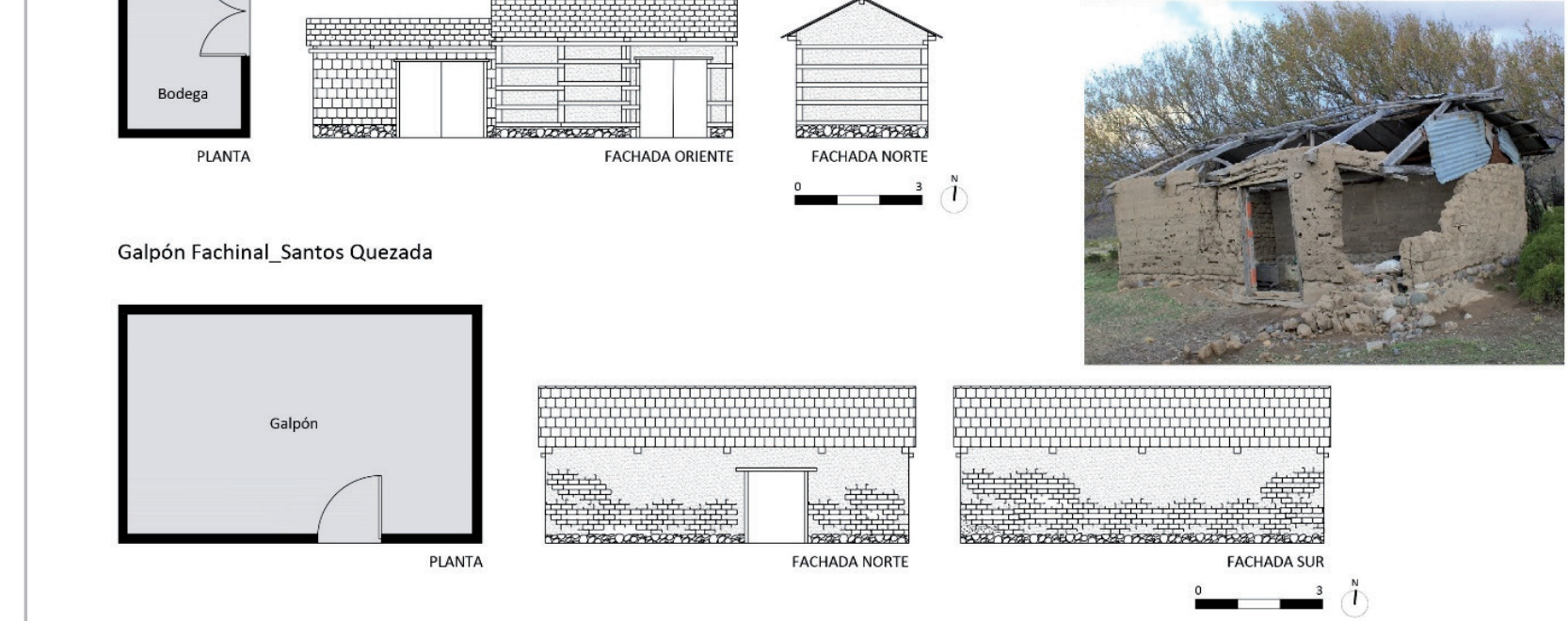

Figura 6.- Proyección planimétrica FA3.

y una leñera-bodega, con una superficie total de $30 \mathrm{~m}^{2}$. Las maderas utilizadas corresponden a las especies $N$. pumilio, Pinus sp., y N. antartica.

El galpón fue construido en la década de 1960, y su materialidad se compone principalmente por bloques de adobe crudo de $20 \times 25 \times 13 \mathrm{~cm}$, revestidos con mortero de barro [Figura 6]. Posee una base de piedras redondas de 15 a $30 \mathrm{~cm}$ de diámetro, enterradas a 35 $\mathrm{cm}$ aproximadamente y 20 a $30 \mathrm{~cm}$ sobre el suelo. La techumbre actual es de planchas de zinc. Las cintas del techo son de $2 \times 3$ pulgadas y separadas cada $30 \mathrm{~cm}$. Posee vigas de $3 \times 3,3 \times 4,3 \times 5,5 \times 4$ y de $5 \times 5$ pulgadas, la soleras horizontales de $4 \times 4$ y $4 \times 5$ pulgadas, piezas de cercha de $4 \times 4$ y $4 \times 5$ pulgadas, todas labradas a hacha. El piso es de tierra. El programa considera una bodega general para la guarda de pastos, animales y otros elementos, con una superficie total de $49 \mathrm{~m}^{2}$. Las maderas utilizadas corresponden a las especies N. pumilio, Pinus sp., y $N$. antartica.

\section{Asentamiento y construcción}

Se obtuvo una regresión lineal significativa entre la altura total y el diámetro del fuste de los árboles estudiados (r2: 0,53) [Figura 7]. Mientras que las edades estimadas tanto para los árboles introducidos como frutales, álamos, sauce, acacia, fresno y ciprés y nativos (Ciprés de las Guaitecas, Coihue de Magallanes, Maitén y Molle (Laura)) estudiados van desde los 44 a los 164 años [Figura 8].

El asentamiento más temprano registrado corresponde a los sectores de Río Avilés, seguido de Fachinal y Mallín Grande [Tabla 1]. Los datos de edad obtenidos de las muestras analizadas coinciden con los periodos de construcción dados a conocer a través de la oralidad por parte de los pobladores/as.

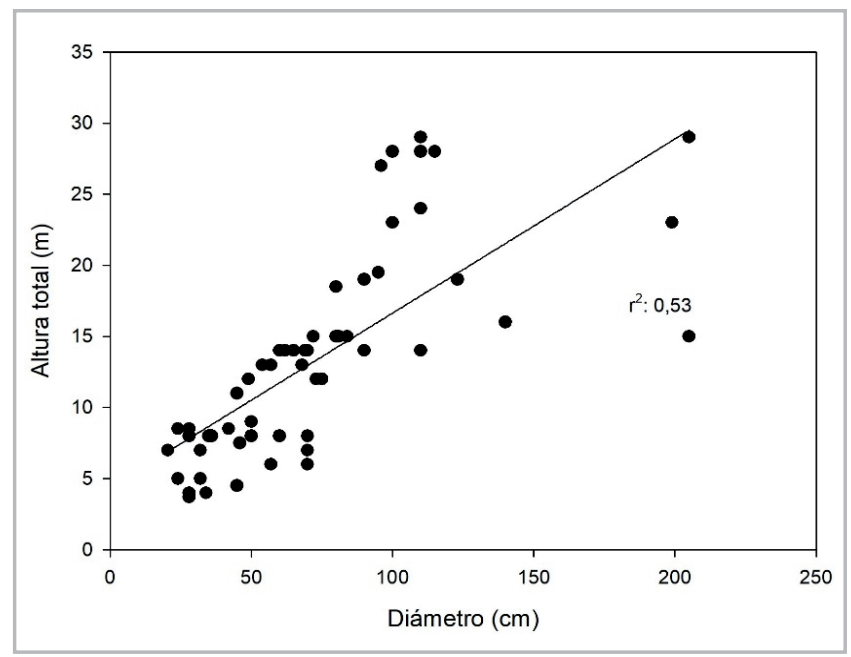

Figura 7.- Análisis de regresión lineal simple entre el diámetro (basal) y la altura total de los árboles muestreados (n: 57). (Elaboración propia). 


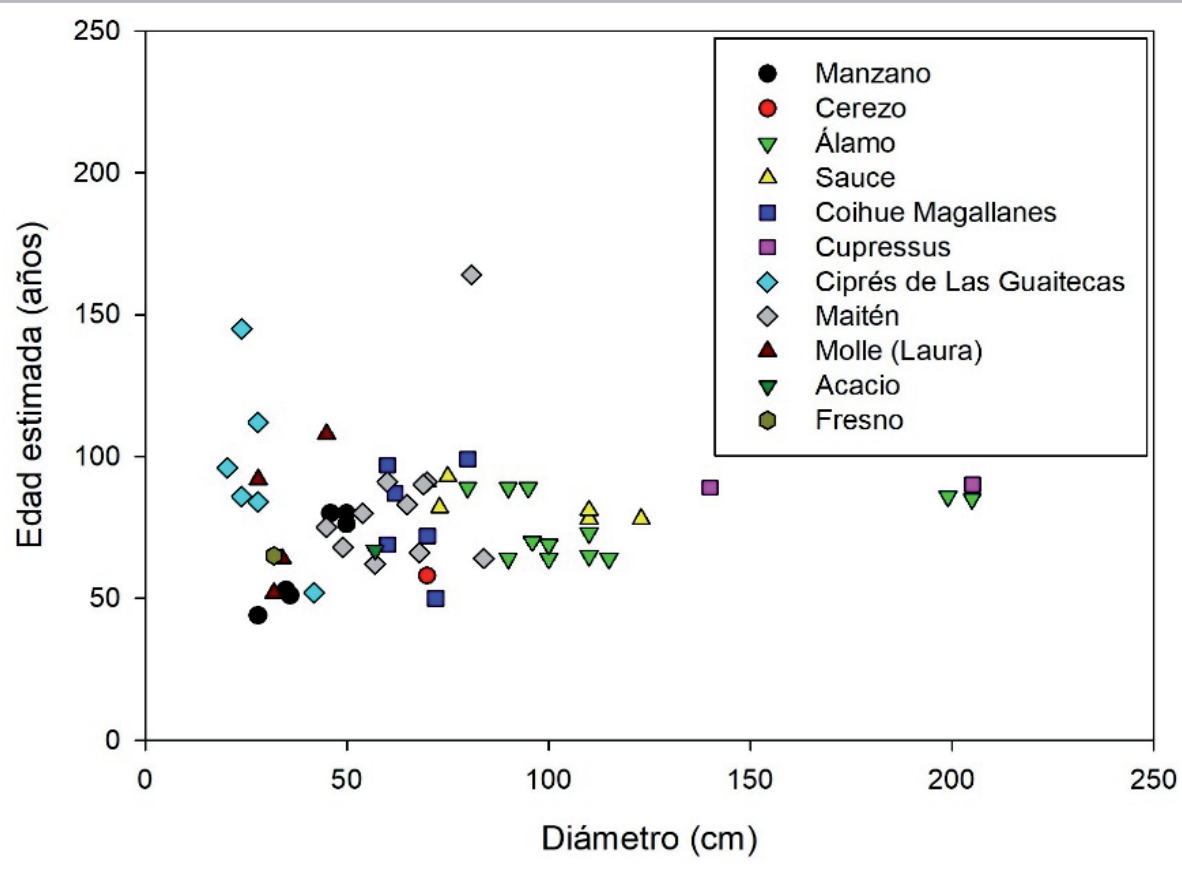

Figura 8.- Análisis de regresión lineal simple entre el diámetro (basal) y la edad estimada (años) de los árboles muestreados (n, 57). (Elaboración propia).

Tabla 1.- Caracterización arbolado de sitios estudiados (n, 57). Región de Aysén, Chile. (Elaboración propia).

\begin{tabular}{|c|c|c|c|c|c|c|c|}
\hline $\begin{array}{l}\text { Poblador/a y } \\
\text { ubicación }\end{array}$ & $\begin{array}{l}\text { Nombre } \\
\text { común } \\
\text { árbol }\end{array}$ & $\mathbf{n}$ & $\begin{array}{l}\text { Altura } \\
\text { total (m) }\end{array}$ & $\begin{array}{l}\text { Diámetro } \\
\text { (cm)" }\end{array}$ & $\begin{array}{l}\text { Edad } \\
\text { estimada } \\
\text { (años) }\end{array}$ & $\begin{array}{l}\text { Periodo construcción } \\
\text { según oralidad** }\end{array}$ & $\begin{array}{l}\text { Característica materiales } \\
\text { usados en adobes y quincha } \\
\text { (oralidad) }\end{array}$ \\
\hline $\begin{array}{l}\text { Modesto } \\
\text { Basualto, } \\
\text { Embarcadero } \\
\text { viejo de Mallín } \\
\text { Grande }\end{array}$ & Álamo & 5 & 28 & 106 & $\begin{array}{l}1944^{*}, 1947^{*} \\
1948^{*}, 1952^{*} \\
1953^{*}\end{array}$ & $\begin{array}{l}\text { Casa construida en la } \\
\text { década de } 1950 .\end{array}$ & $\begin{array}{l}\text { Los adobes son de greda } \\
\text { mezclada con coirón y restrojos } \\
\text { de trigo y avena. Las paredes } \\
\text { revocadas con greda común. }\end{array}$ \\
\hline \multirow{3}{*}{$\begin{array}{l}\text { Celestino } \\
\text { Epifanio, } \\
\text { Río Avilés, } \\
\text { Fachinal-Chile } \\
\text { Chico }\end{array}$} & Álamo & 3 & 19 & 88 & $\begin{array}{l}1929 *, 1929 * \\
1929 *\end{array}$ & \multirow{3}{*}{$\begin{array}{l}\text { El primer rancho y/o } \\
\text { puesto fue de palo partido } \\
\text { y canogas construido en la } \\
\text { década de } 1920 \text { por don } \\
\text { Celestino Epifanio (Q.E.P.D.), } \\
\text { actualmente no existe y } \\
\text { solo quedan vestigios de los } \\
\text { álamos plantados y restos } \\
\text { de madera. El rancho y/o } \\
\text { puesto de quincha (pared } \\
\text { francesa y/o bahareque) } \\
\text { fue construido entre } 1935 \text { a } \\
\text { principios de } 1940 . .\end{array}$} & \multirow{3}{*}{$\begin{array}{l}\text { Las paredes están compuestas } \\
\text { por un entramado de varas } \\
\text { de ciprés, arbustos como la } \\
\text { azara, la laura, el duraznillo, } \\
\text { el romerillo, ramas de coihue, } \\
\text { trozos de turba y piedras }\end{array}$} \\
\hline & $\begin{array}{l}\text { C i p r é s } \\
\text { de } \quad \text { Las } \\
\text { Guaitecas }\end{array}$ & 6 & 7,5 & 28 & $\begin{array}{l}1832 a, \quad 1922, \\
1906 a, 1966, \\
1873 a, 1934\end{array}$ & & \\
\hline & $\begin{array}{l}\text { Coigüe de } \\
\text { Magallanes }\end{array}$ & 6 & 12 & 67 & $\begin{array}{l}\text { 1921a, 1946, } \\
\text { 1949, 1919a, } \\
1931,1968\end{array}$ & & \\
\hline \multirow{7}{*}{$\begin{array}{l}\text { Fica Burgos, } \\
\text { Fachinal-Chile } \\
\text { Chico }\end{array}$} & Álamo & 2 & 21 & 147 & $1933 *, 1954$ & \multirow{7}{*}{$\begin{array}{l}\text { Casa vieja construida entre } \\
1925 \text { a 1930. La casa nueva } \\
\text { actualmente está habitada } \\
\text { por sus descendientes, hija } \\
\text { y nietos, y fue construida } \\
\text { desde } 1930 \text { aprox. en } \\
\text { adelante. }\end{array}$} & \multirow{7}{*}{$\begin{array}{l}\text { Los adobes originales de } \\
\text { ambas casas están elaborados } \\
\text { de greda mezclada con coirón } \\
\text { y guano de caballo. Los más } \\
\text { recientes poseen restrojos de } \\
\text { trigo y cebada que se cultivaba } \\
\text { antiguamente. Y también se } \\
\text { ha utilizado el pasto dulce } \\
\text { común. Las paredes revocadas } \\
\text { con greda común. }\end{array}$} \\
\hline & Sauce & 3 & 15,6 & 114 & $\begin{array}{c}1937^{*}, 1937^{*} \\
1940\end{array}$ & & \\
\hline & $\begin{array}{c}\text { Ciprés } \\
\text { Macrocarpa }\end{array}$ & 2 & 15,5 & 172 & $1928^{*}, 1929^{*}$ & & \\
\hline & Maitén & 5 & 13,5 & 63 & $\begin{array}{c}1927^{*}, 1927^{*} \\
1943,1954 \\
1956\end{array}$ & & \\
\hline & $\begin{array}{l}\text { Molle y/o } \\
\text { Laura }\end{array}$ & 4 & 4 & 35 & $\begin{array}{c}\text { 1910b, } 1926 * \\
1954,1966\end{array}$ & & \\
\hline & Fresno & 1 & 7 & 32 & 1953 & & \\
\hline & Cerezo & 1 & 7 & 70 & 1960 & & \\
\hline
\end{tabular}




\begin{tabular}{|c|c|c|c|c|c|c|c|}
\hline \multirow{3}{*}{$\begin{array}{l}\text { José Ahuil, } \\
\text { El Manzano, } \\
\text { Fachinal-Chile } \\
\text { Chico }\end{array}$} & Sauce & 3 & 10 & 72,6 & $\begin{array}{c}1925^{*}, 1927^{*} \\
1936\end{array}$ & \multirow{3}{*}{$\begin{array}{l}\text { La casa vieja fue construida } \\
\text { entre } 1925 \text { a } 1935 \\
\text { aproximadamente, por } \\
\text { el poblador José Ahuil } \\
\text { (Q.E.P.D.). La casa nueva fue } \\
\text { construida en la década } \\
\text { de } 1960 \text { en adelante por la } \\
\text { familia Muñoz Inallao. }\end{array}$} & \multirow{3}{*}{$\begin{array}{l}\text { Los adobes de ambas casas } \\
\text { fueron elaborados con greda, } \\
\text { coirón y guano. Se usaron } \\
\text { también restrojos de trigo, } \\
\text { avena y cebada. Paredes } \\
\text { revocadas con greda común. }\end{array}$} \\
\hline & Manzano & 3 & 8 & 40 & $\begin{array}{c}1942,1965 \\
1967\end{array}$ & & \\
\hline & Álamo & 3 & 23 & 136 & $\begin{array}{c}1932^{*}, 1953 \\
1954\end{array}$ & & \\
\hline $\begin{array}{l}\text { Santos } \\
\text { Quezada, } \\
\text { fachinal-Chile } \\
\text { Chico }\end{array}$ & Manzano & 1 & 4 & 28 & 1974 & $\begin{array}{l}\text { El rancho y/o puesto y el } \\
\text { galpón fueron construidos } \\
\text { de la década de } 1940 \text { en } \\
\text { adelante por el poblador } \\
\text { Santos Quezada (Q.E.P.D.). }\end{array}$ & $\begin{array}{l}\text { La pared del puesto está } \\
\text { compuesta por un entramado } \\
\text { de arbustos como la laura, } \\
\text { el duraznillo, el romerillo, y } \\
\text { ramas de maitén. Los adobes } \\
\text { del galpón poseen una mezcla } \\
\text { de greda, coirón, restrojos de } \\
\text { avenay trigo. Paredes de ambas } \\
\text { construcciones revocadas con } \\
\text { greda común. }\end{array}$ \\
\hline \multirow{2}{*}{$\begin{array}{l}\text { s.i., Mallín } \\
\text { Grande }\end{array}$} & Manzano & 2 & 7,5 & 48 & $1938^{*}, 1938^{*}$ & \multirow{2}{*}{$\begin{array}{l}\text { La casa de quincha fue } \\
\text { construida entre los años } \\
1926 \text { a } 1938\end{array}$} & \multirow{2}{*}{$\begin{array}{l}\text { La pared está compuesta por } \\
\text { un entramado de arbustos } \\
\text { como la laura, duraznillo y } \\
\text { ramas de maitén. La pared esta } \\
\text { revocada con greda común } \\
\text { y posee restos de huesos de } \\
\text { animales en algunas secciones. }\end{array}$} \\
\hline & Maitén & 6 & 12 & 60,5 & $\begin{array}{c}\text { 1855b, 1929*, } \\
1936^{*}, 1939 \\
1951,1953\end{array}$ & & \\
\hline
\end{tabular}

“Diámetro promedio del árbol medido a los $30 \mathrm{~cm}$ de altura y donde se extrajo el tarugo para determinar la edad en años.

** Periodo de construcción aproximado dado a conocer a través de la entrevista oral.

* Árboles cuyo dato de fechado de anillos de crecimiento anual concuerda con datos del periodo de construcción de la arquitectura vernácula en tierra dados a conocer en la oralidad.

a: Ciprés de Las Guaitecas (P. uviferum) que corresponde a un relicto de la especie desarrollándose en una condición de transición bosque-estepa y cuyos árboles de mayor diámetro (más viejos) fueron utilizados para construir tanto la habitación como los cierres perimetrales en el sector. Previa a su explotación, este bosque fue quemado para acceder con mayor facilidad y hacer la madera más liviana y fácil de transportar, lo que llevó a que actualmente este bosque no posea individuos de avanzada edad que permitan estimar con certeza su edad original. Con respecto a los árboles de Coihue, estos corresponden a individuos que se desarrollaron post-incendio y cuyos ejemplares más viejos igualmente fueron explotados y su madera utilizada para la construcción, cierres y otros usos dentro de la zona de estudio (ej. como combustible leña), situación compartida por maitén.

b: Edad que da cuenta que el árbol de Molle (Laura) y el de Maitén son anteriores a la llegada de los pobladores/as y estos fueron utilizados como semilleros para los árboles de la misma especie que fueron plantados en los potreros aledaños a la construcción en tierra.

\section{Técnicas de construcción utilizadas}

El hacha y la azuela fueron las herramientas esenciales para trabajar la madera (Castillo y Pérez 2019: 100), posteriormente la llegada de otras herramientas más sofisticadas como la tronzadora (trozadora), los serruchones, la sierra a brazo y las machetas tejueleras, permitió a los carpinteros comenzar a elaborar piezas más elaboradas, destacando entre estas las vigas, soleras, pies derechos, cerchas, cintas, tablas y la tejuela rajada. Muchas de estas herramientas fueron adquiridas y traídas desde territorio argentino por parte de los pobladores/as, mientras que otras fueron mandadas a confeccionar a los herreros que había en esos años (Castillo 2015: 18).

Cuando dentró mi papá (Cipriano Alarcón Roa Q.E.P.D.) a este sector, su primera casa fue un ranchito, de canogas y palo amordazado. Esto era pura montaña, de cañal tupido y arbustos. Todos los víveres, las herramientas, clavos y otros enseres se iban a buscar a la Argentina, en pilcheros, un par de semanas duraban los viajes, vadeando los ríos y cruzando cerros, aguantando el fuerte viento de la pampa. (Cipriano
Alarcón, entrevista personal, Lago Lapparent, octubre de 2016)

Gran parte de los materiales de la casa vieja y la más nueva, fueron traídos desde Argentina y desde Puerto Aysén. Los viajes se hacían a caballo con pilcheros y en chata. Luego se cruzaba por el lago en embarcaciones bien sencillas que aguantaban la travesía y el tiempo malo. Una vez llegados los víveres, materiales y variados enseres como las herramientas básicas (serruchos, serruchones, tronzadoras, la sierra a brazo, cepillos, taladros, azuelas, los clavos, etc.) mi abuelo (Uberlindo Fica Rivera Q.E.P.D.) junto a otros familiares y conocidos trasladaban las cosas en carreta tirada por bueyes al sitio donde se estaba construyendo. (Rodrigo Fica Soto, entrevista personal, Fachinal, mayo de 2019)

Para la confección del adobe, se utilizó la adobera y/o gavera (Sánchez 2007: 247; Guerrero 2007: 92; Rivera 2012: 168) que dio las dimensiones de cada bloque (largo, ancho y espesor). Se identificaba y seleccionaba el área con la mejor greda para posteriormente hacer un pozo abierto, 
una cantera, en el mismo predio de construcción, (a cielo abierto, Sánchez 2007: 247) de un diámetro por sobre los 6 metros, y de $40 \mathrm{~cm}$ de profundidad. La paja (Festuca $s p$. Coirón) se seleccionaba y cortaba de los potreros de alimentación del ganado, y el guano usado era de caballo [3] La mezcla (greda+paja+guano) Ilamada pastón se hacía con la ayuda de caballos y posteriormente las mismas personas terminaban de pisotear y mezclar bien para luego ir llenando las adoberas (individual o doble). Los adobes listos se iban ordenando de tal forma que se orearan y secaran en un par de días con la ayuda del viento y sol, para posteriormente ser utilizados en la construcción de la casa, cocina fogón y/o galpón. El mortero utilizado como estuco para la pared tanto al exterior como al interior fue la misma greda y/o barro con que se elaboró el adobe (Lara et al. 2020: 74-75).

El adobe que ocupó la casa vieja, fue hecho aquí mismo, ahí donde está la cantera. Se ubicaba y seleccionaba el lugar donde estaba la mejor greda, en esta se hacía un hoyo grande y no muy profundo, se mezclaba la greda con pasto, agua y caca de caballo. Se iba sacando la mezcla y echándola a los moldecitos de madera (adoberas) para darle la forma y medida. Estos se iban dejando ordenados para que se fueran secando lentamente al viento y al sol, y se tenía el cuidado que no se secaran de golpe para que no se partan. (Segundo Burgos Hermosilla, entrevista personal, diciembre de 2017)

Mi abuelo participó directamente en la construcción de estas dos casas de adobe, madera y piedra, de él heredamos esta sabiduría de valorar los elementos naturales que tenemos disponible para construir; donde está la greda o barro adecuado, el tipo de coirón, el guano, cómo mezclar todo esto y comenzar a jugar con el molde, elegir las piedras, y las canteras para obtener el material en el tiempo. El saber hacer la adobera, tener nociones del tiempo (clima) para trabajar mejor y tantas otras cosas que uno va a prendiendo con la práctica. (Rodrigo Fica Soto, entrevista personal, Fachinal, mayo de 2019)

Con respecto a la técnica de la quincha, la greda se obtenía también en el mismo lugar (muy abundante en todos los sitios bajo estudio) y esta se usaba en forma pura o mezclada con paja (coirón y pasto dulce) y guano de caballo (Guerrero 2007: 96; Sánchez 2007: 250; Jorquera 2015: 7). En cada construcción se hacía primeramente un entramado primario de varas labradas y/o aserradas de distinto tamaño, acompañadas de un tejido secundario con ramas de diversos arbustos y un relleno de barro al interior. Como mortero para estuco para el exterior e interior de las paredes se llegaron a utilizar restos de huesos de animales para entremezclarlos con la greda. Se utilizaron también trozos de turba y piedras redondas de tamaño pequeño, y un entramado de arbustos como pared principal sin relleno interior y revocada tanto al exterior, como al interior con greda (Esteves y Cuitiño 2020: 96).

Una de las primeras construcciones que levantaron Natanael Fuenzalida y Rosa Rojas (Q.E.P.D.) fue de pared francesa, compuesta de un entramado de madera labrada a hacha, rellenada al interior con barro, paja y ramas de arbustos. Esta fue de dos pisos, tenía un corredor frontal, una cocinacomedor y una habitación en la planta baja y otras tres en el segundo piso. Ahí vivieron hartos años, hasta que comenzaron a construirse una casa más grande y completamente de madera labrada y aserrada. (Crispín Castillo Castillo, entrevista personal, Coyhaique, octubre de 2019)

Don José Ríos Monsalve y Filomena Vásquez llegaron al sector de Cerro Galera el 37 (1937), y el primer rancho que construyó el matrimonio fue de pared francesa. Hicieron un entramado de palos labrados y lo rellenaron con trozos de pasto, tierra y ramas de árboles, y con piso de tierra. Vivieron varios años en este ranchito. (Ramón Mardones, entrevista personal, Cerro Galera, junio de 2019)

\section{Discusión}

En la región de Aysén y en particular en la zona bajo estudio, los pobladores/as trajeron consigo el conocimiento de las técnicas constructivas como herencia cultural desde sus lugares de origen, lo que les permitió hacer frente a una serie de requerimientos constructivos propios de la zona (Castillo y Pérez 2019: 107), y adaptarse al nuevo territorio en ocupación.

Con respecto a la datación de los árboles introducidos y nativos de cada caso constructivo estudiado (Tabla 1), los resultados permiten contar con un registro decidor en torno a los periodos de llegada, establecimiento y construcción de los inmuebles por los pobladores/as de Fachinal, Río Avilés y Mallín Grande. La dendrocronología como herramienta de análisis para precisar y corroborar la información entregada por las fuentes orales, representa una fuente inequívoca de información a contrastar con la obtenida de las entrevistas, pues ésta última al no ser obtenida de la fuente primaria, es decir, de la primera generación, con el paso del tiempo va perdiendo precisión (Castillo y Pérez 2019: 103).

Los sistemas constructivos estudiados guardan similitud con las técnicas de otros territorios del país y del continente. Ejemplo claro es la elaboración del adobe como material constructivo y cuyo proceso de fabricación lo describe bien Rivera (2012: 170), quien destaca tres etapas básicas, que son la identificación y selección del suelo y materiales complementarios, la preparación y moldeado, y el secado y la fabricación misma del adobe. Una técnica que no ha sufrido grandes cambios pese a las condiciones geográficas tan distintas entre un territorio y otro (Sánchez 2007: 245). Un diagrama de fabricación que de alguna manera se ha insertado en la memoria del ser humano, viajando a lugares recónditos y volviendo a tomar una forma viva y tangible, que se adapta a las condiciones de cada territorio y para un periodo específico. Existe una especialización en el tipo de confección del muro de adobe, que puede ser a través de la utilización del lado corto del bloque, conocido como 
muro soga, o muro doble que utiliza con preferencia el lado largo del adobe (Guerrero 2007: 193; Tomasi 2012: 14). Por otro lado, algunas construcciones presentan adobes expuestos, sin revoque, aunque las más viejas pueden presentar hasta dos capas y/o manos de greda al natural (Lara et al. 2020: 74-75), sin la utilización de cal, y a esto se suma un cimiento y sobre cimiento basal de piedra de tamaño irregular (Sánchez 2007: 245; La Spina 2016: 126), para evitar el contacto directo con el agua o la humedad del suelo (Esteves y Cuitiño 2020: 98).

Con respecto a las cubiertas de una, dos y cuatro aguas, en la zona bajo estudio (ribera sur-poniente del lago General Carrera) se replicaron dos técnicas que son descritas por Tomasi (2012) en su estudio de construcciones puneñas (Susques, provincia de Jujuy, Argentina) la torta de barro y el guayado: la primera basada en la ejecución de toda la cubierta de una o dos capas de greda mezclado con paja (junquillo, coirón y/o pasto dulce), y la segunda consistente en sucesivas hileras de manojos de paja sobre un entramado de madera. Este tipo de techumbre no se observa actualmente en la zona de estudio, sin embargo, se ha corroborado su existencia en el pasado a través de los testimonios orales: Muchos pobladores que hicieron sus casas de adobe y quincha, no utilizaron la tejuela o el zinc para los techos, lo que se utilizó fue el junquillo en varias capas o la paja mezclada con barro. Ahora ya no se ven esos techos .(Guillermo Muñoz Inallao, entrevista personal, Fachinal, mayo de 2019).

Para el caso de la quincha, las diferencias marcadas entre una construcción y otra se ven específicamente en el tipo de tierra utilizado (Gama et al. 2012: 182), la textura y composición del barro, los tipos de madera y piedras, las dimensiones, la forma de trabajar, la disposición u orden de colocación de los elementos en la construcción, y el tipo de constructor/a (Sánchez 2007: 251; Tomasi 2012:15; Jorquera 2015: 7; Fullerton y Medina 2017: 151).

En contexto y retomando la interrogante planteada al inicio del presente trabajo, la arquitectura estudiada representa un importante vestigio de autoconstrucción que se adaptó a las condiciones propias del territorio definiendo una forma particular de utilizar los materiales disponibles, lo que también derivó en un enriquecimiento del conocimiento empírico traído desde otros territorios. Los casos estudiados son construcciones sencillas y con un diseño en pequeña escala, que se constituyen como piezas fundamentales para el estudio y la comprensión del modo de ocupación que tuvo la población euro-chilena, asentada entre principios y mediados del siglo XX en la ribera surponiente General Carrera, región de Aysén.

\section{Conclusiones}

La técnica constructiva en adobe y quincha, estudiada en esta zona en específico, no ha sufrido grandes variaciones respecto de la técnica procedente de otras zonas geográficas. Sin embargo, el tipo de material local utilizado para construirlo y el modo en que éste se asocia a nuevos recursos constructivos propios de la zona, constituyen un factor diferenciador de lo que hasta ahora se ha registrado en la región de Aysén. Para el adobe, el material vegetal predilecto utilizado fue el coirón, sumándose más tardíamente el pasto dulce, los restrojos del trigo y la cebada. Y a la quincha se le agregaron arbustos como la azara, la laura, el duraznillo, el romerillo, ramas de coihue y maitén, trozos de turba y piedras para dar mayor consistencia al muro, así como huesos de animales mezclados con la greda. Estos nuevos rasgos incorporados a la técnica tradicional de construcción en adobe y quincha, permiten fortalecer la identidad de una arquitectura vernácula local única en su tipo constructivo y única para la región.

A través de este trabajo se logra rescatar y poner en valor los conocimientos constructivos de los pobladores/as pertenecientes a la ribera sur-poniente del Lago General Carrera, cuyo saber adquirido desde otros lugares, les permitió establecerse y hacer uso de los materiales locales a disposición, para traducirlo en una técnica más enriquecida. En contexto, los casos registrados e investigados dan cuenta de una arquitectura vernácula en tierra con rasgos propios, que vienen a complementar los conocimientos actuales sobre arquitectura vernácula en el territorio de Aysén.

Los resultados obtenidos validan la importancia de reconocer este tipo de arquitectura existente en la ribera sur-poniente del lago General Carrera, y dan cuenta de la diversidad de técnicas de construcción y tipologías que los pobladores llegados espontáneamente lograron erigir en concordancia con las condiciones geográficas y climáticas imperantes.

Teniendo en cuenta la similitud de la autoconstrucción en tierra del área del presente estudio con otros territorios de latitud geográfica diferente, cabe preguntarse; ¿Qué características propias de los materiales en esta zona han influido en la permanencia de éste tipo de construcciones en el tiempo? ¿Cómo los constructores han adquirido el conocimiento de las proporciones exactas para fabricar un elemento que perdure por décadas? ¿Cómo y de qué forma se ha dado la interacción entre el conocimiento empírico de cada poblador y la adaptación de la técnica, según los recursos y condiciones climáticas de la zona?, ¿Cómo estas condiciones han influido en la permanencia de este tipo de edificaciones por más de 90 años?, ¿Cómo se transformó el paisaje habitado a partir de esta práctica constructiva y cuáles son las huellas existentes que dan cuenta de este proceso?

Estas preguntas podrán ser respondidas en la medida que se profundicen los estudios tendientes a la caracterización de la arquitectura vernácula en tierra existente en el área de estudio y en la región, siendo el presente artículo un trabajo de salvaguarda de este patrimonio constructivo que pretende impulsar la investigación en cuestión. 


\section{Agradecimientos}

A las familias propietarias de los sitios estudiados de Mallín Grande, Río Avilés y Fachinal, Chile. A los pobladores Rodrigo Soto Fica, Adolfo y Guillermo Muñoz Inallao, y Gumersindo Burgos Hermosilla por el apoyo en terreno y la información entregada. A María Paz Canales y Bárbara Barrientos, estudiantes de arquitectura de la Pontificia Universidad Católica de Chile.

\section{Notas}

[1] Entejuelado-Entejuelar: Acción de colocar la tejuela clavada sobre el encintado, tanto en el techo como en la pared (tinglado) de la construcción.

[2] El primer techo fue de un entramado de varas labradas a hacha, barro y paja, que posteriormente fue reemplazado por tejuela artesanal rajada.

[3] Una de las principales funciones del estiércol o guano radica en la incorporación de fibras vegetales que han sido trituradas en el trasto digestivo por el ganado y que son de fácil obtención en los sitios rurales (Guerrero 2007: 190).

\section{Referencias}

CASTILLO LEVICOY, C. (2015). "Distribución geográfica de la arquitectura vernácula con tejuela artesanal, región de Aysén", Conserva, 20: 7-21.

CASTILLO LEVICOY, C., PÉREZ LIRA, C. (2019). “Caracterización de la arquitectura vernácula en madera de complejos constructivos rurales, región de Aysén, Chile". Intervención 19: 99-110.

DIRECCIÓN METEOROLÓGICA DE CHILE (2010). “Descripción meteorológica, Undécima región" Documento técnico de la Dirección General de Aeronáutica Civil, Chile.

DUNCAN, R. P. (1989). "An Evaluation of errors in Tree age Estimates based on Increment Cores in Kahikatea (Dacrycarpus dacrydioides)" New Zealand Natural Sciences 16: 31-37.

ESTEVES, J. M., CUITIÑO G. (2020). "El sistema constructivo de la quincha en zonas rurales del norte de Mendoza (Argentina)". Estoa (Revista de la Facultad de Arquitectura y Urbanismo de la Universidad de Cuenca) 17: 93-102.

FULLERTON, D., MEDINA P. (2017). Saberes Arquitectónicos. Las Formas Vernáculas del Antiplano. Ril Editores, Santiago, Chile. 200p.

GAMA, J., CRUZ, T., PI-PUIG, T., ALCALA ,R., CABADAS, H., JASSO, C., DÍAZ, J., SÁNCHÉZ, S., LÓPEZ, F., VILANOVA DE ALLENDE, R. (2012). "Arquitectura de tierra: el adobe como material de construcción en la época prehispánica". Boletín de la Sociedad Geológica Mexicana 64: 177-188.
GUERRERO, L. (2007). “Arquitectura en tierra. Hacia la recuperación de una cultura constructiva". Apuntes 20: 182-201.

HEPP, C., STOLPE, N. (2014). Caracterización y propiedades de los suelos de la Patagonia Occidental (Aysén). Boletín № 298. Instituto de Investigaciones Agropecuarias (INIA).

JORQUERA, N. (2015). "Aprendiendo del Patrimonio Vernáculo: tradición e innovación en el uso de la quincha en la Arquitectura Chilena". Revista de Arquitectura, № 28/29: 4-11.

LARA, M., SANZ D., DEL PINO, I. (2020). "Morteros históricos en las construcciones de Quito de los siglos XVI, XVII y XVIII". Geconservación 17: 71-81.

LA SPINA, V. (2016). "Tierra y yeso en la arquitectura tradicional murciana". $P+C$ 07:119-132.

PÉREZ, L., ERRÁZURIZ, T., CASTILLO, C. (2018). Casas en el valle Simpson, el patrimonio desconocido de Aysén. Andros LTDA, Santiago, Chile. 164p.

RIVERA, J. (2012). "El adobe y otros materiales de sistemas constructivos en tierra cruda: caracterización con fines estructurales". Apuntes 25: 164-181.

SÁNCHEZ, C. (2007). "La arquitectura de tierra en Colombia, procesos y culturas constructivas". Apuntes 20: 242-255.

TOMASI, J., RIVET, C. (2009). Puna y Arquitectura. Las formas locales de construcción. Ministerio de Educación de la Nación, Susques, Argentina. 176p.

TOMASI, J. (2012). “Lo cotidiano, lo social y lo ritual en la práctica del construir. Aproximaciones desde la arquitectura puneña (Susques, provincia de Jujuy, Argentina)". Apuntes 25: 8-21.

\section{Autor/es}

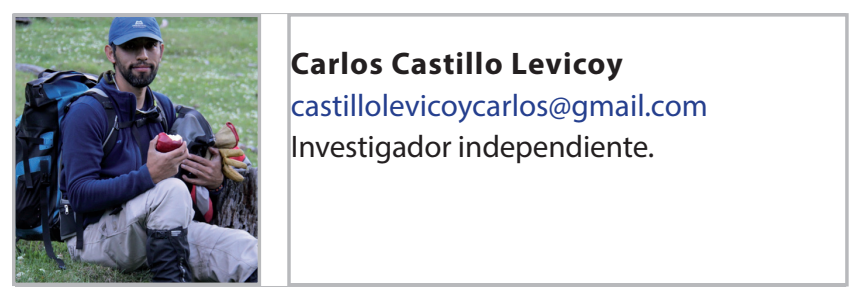

Ingeniero Forestal de la Universidad Austral de Chile. Curso un Magíster en Ciencias con Mención en Botánica, Universidad de Concepción. Su trabajo de investigación durante los últimos años ha estado enfocado a la puesta en valor de los oficios tradicionales madereros y a estudiar la arquitectura vernácula regional, que le han permitido publicar varios trabajos entre papers y libros, junto a otros profesionales. Es director editor de la Revista de Investigación Regional Aysenologia (www.aysenologia.cl), y junto a la arquitecta Constanza Pérez Lira, están impulsando el estudio y la puesta 
en valor de la arquitectura vernácula a través de la iniciativa "Vernácula Aysén". Reside en la región de Aysén, donde trabaja actualmente como consultor e investigador en el área forestal y tecnología de la madera.

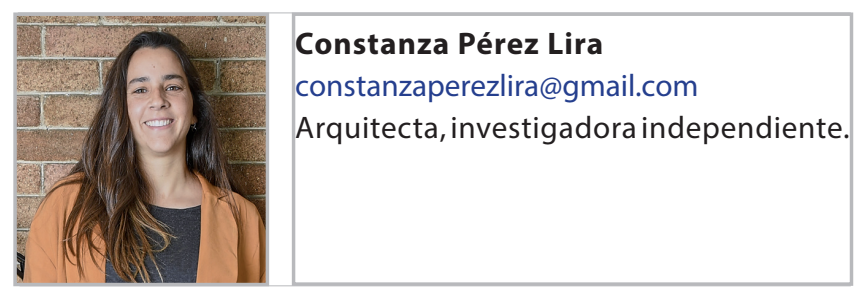

Arquitecta de la Universidad Católica de Chile y socia fundadora de la Corporación Memoria Austral. Postulante a Magíster Historia del Arte de la Universidad Adolfo Ibáñez. Tras haber vivido cinco años en la región de Aysén, se ha dedicado al estudio y rescate del patrimonio cultural, buscando la puesta en valor de la cultura local a partir de proyectos de investigación arquitectónica y de creación artística. Junto a Carlos Castillo Levicoy, han impulsado Aysén Vernacular, iniciativa que busca rescatar y difundir la arquitectura vernacular de la Región de Aysén, como herramienta de salvaguarda de la arquitectura patrimonial local. A través de esta plataforma han publicado diferentes papers, libros y han llevado a cabo proyectos y exposiciones que exploran el habitar en Aysén, según sus diferentes realidades geográficas y para el registro de aquellos elementos culturales que componen el imaginario Aysenino. Para mayor información, visitar www.memoriaaustral.cl

Artículo enviado el 10/05/2020

Artículo aceptado el 14/08/2020

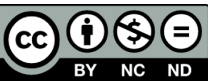

https://doi.org/10.37558/gec.v18i1.769 